\title{
Bacterial Cold Shock Proteins - the Molecular Chaperones for Multiple Stress Tolerance
}

\author{
Rajasheker $\mathrm{G}^{1}$, Anil Kumar $\mathrm{S}^{2}$, Hima Kumari $\mathrm{P}^{1}$ and Kavi Kishor PB ${ }^{1 *}$ \\ ${ }^{1}$ Department of Genetics, Osmania University, India \\ ${ }^{2}$ Department of Biotechnology, Vignan's Foundation for Science, Technology and Research, India
}

Submission: November 12,2018; Published: January 22, 2019

*Corresponding author: Kavi Kishor PB, Department of Genetics, Osmania University, Hyderabad 500 007, India

\begin{abstract}
Bacteria overcome the cold environmental conditions by inducing cold shock proteins (Csps) in response to rapid downshift temperature. Due to cold shock, membrane fluidity decreases, resulting in stabilization of nucleic acid secondary structures and impairment of overall metabolic activities. Csps are highly conserved structural proteins that bind to RNA binding motifs RNP-1 and RNP-2. Cold Shock Domain (CSD) is the characteristic feature of Csps, and conserved across bacteria, animals, and plants. However, in humans, CSD are represented as Y-box proteins. Csp homologs have been identified in plants which play a major role in cold, salt, and drought stress tolerance. Overexpression of Csps in plants resulted in high accumulation of proline, antioxidative activity with improved yield. The present mini-review focuses on the activity of Csps with special emphasis on their homologs which has not been covered earlier.
\end{abstract}

Keywords: Chaperones; Cold shock domain; Cold shock proteins; homologs; stress

Abbrevations: CSPs: Cold Shock Proteins; CSD: Cold Shock Domain; CIPs: Cold-Induced Proteins; E. coli - Escherichia coli; PNP: Polynucleotide phosphorylase; RNP-1: RNA binding motif1; RNP-2: RNA binding motif2

\section{Introduction}

Bacteria encounter different changing environments but resist the environmental changes by developing an array of mechanisms which protect them from adverse conditions. During cold conditions, fluidity of cell membranes decreases, and this results in lowering of active transport and protein secretion [1]. Further, all the molecular mechanisms gets impaired due to stabilization of secondary structures of DNA, RNA, and proteins [2]. RNA binding proteins (RNA chaperones) are ubiquitous and found in all living organisms and help to resolve the misfolded RNA structures under abiotic stress conditions. During rapid drop in temperatures, cold-induced proteins (Cips) are produced to protect the cells. With an increase in the cold conditions, the production of Cips also increases [3]. Different types of Cips like cold shock protein (Csp) family, RNA helicase csdA, exoribonucleases, PNPase and RNaseR, initiation factors 2a and 2b, NusA, and RecA [4-7] have been identified in Escherichia coli (E. coli). The Csps are one of the major Cips produced under cold conditions mainly in bacteria $[4,8]$.

The Csps are the small, acidic, nucleic acid-binding proteins ranging from 65 to 75 amino acids that are highly induced during low temperature conditions and serves as RNA chaperons to prevent the misfolding of mRNA [9]. Based on sequence similarity (46-91\%), a total of 9 Csps (CspA, B, C, D, E, F, G, H, and I) have been identified in E. coli and 3Csps (CspB, CspC, CspD) in Bacillus, 5 Csps (cspA to cspE) in Lactococcus lactis and 3 Csps (CspL, P, and C) in Lactococcus plantarum respectively $[4,8,10,11]$. Later, Csps and its homologs were identified in several bacteria, animals and plants [12]. Of the 9 E. coli Csps, 4 are induced by cold (CspA, CspB, CspG and CspI), 1 by starvation (CspD), 2 (CspC and CspE) show constitutive expression at $37{ }^{\circ} \mathrm{C}$, and 2 are uncharacterized proteins ( $\mathrm{CspF}$ and $\mathrm{CspH}$ ) [13-19]. Acinetobacter oleivorans CspE is also induced by cold shock [20]. Earlier, Horn et al. [19] reviewed the structure and functions of Csps and Keto-Timonen [21] reviewed the role of Csp family with a focus on Yersinia. The present mini-review describes the activity of Csps with emphasis on Csp homologs which has not been covered earlier. Also, a note is added on how these Csps protected the bacterial systems against the cold temperatures.

\section{Structure and characterization of Csps}

High structural conservation was noticed among Csps, but with variable thermostability. The melting temperature of Csps of Thermus aquaticus was as high as $76{ }^{\circ} \mathrm{C}$ with more rigid structure which infers higher structural flexibility is needed to accommodate nucleic acids upon cold shock [22]. The half-life of Csps also increases upon cold shock from 12 seconds to 20 minutes [23]. It has also been pointed out that the CspA mRNA adopts 
to different stable secondary functional structures by thermosensing the environmental temperature $[24,25]$. Csps show highly conserved CSD domain proteins, with approximate molecular weights7.4 KD, which specifically bind to single stranded nucleic acids (ssDNA and ssRNA), but unlikely to bind to double stranded DNA [26]. Csps also known as RNA binding proteins, interact with nucleic acids through moderately conserved conical forms of RNA binding motifs RNP-1 (K/R-G-F/Y-G/A-F-V/I-X-F/Y) and RNP2 (L/I-F/Y-V/I-G/K-N/G-L) [19]. Nuclear Magnetic Resonance (NMR) studies revealed five $\beta$ strands that are arranged into an antiparallel $\beta$-pleated sheet forms. One is a closed $\beta$ barrel, two are $\beta$ sheet surfaces, and the barrel is stabilized by the hydrophobic interactions between two $\beta$-pleated sheets $\beta 1$ and $\beta 2$. Similarly, $\beta 2$ and $\beta 3$ are interconnected by very short loops L1 and $\mathrm{L} 2$ respectively as well as L3 and L4 are connected by $\beta 3$ and $\beta 4, \beta 4$ and $\beta 5$ respectively, and L3 loop contains small $\alpha$ helicals in TmCsp (Thermotoga maritime) [27].

It has been shown that CspA co-operatively binds to RNA and ssDNA and upon CspA binding, the RNA substrate becomes more sensitive to nuclease digestion. This suggests that CspA functions as an RNA chaperone to prevent secondary structure formation in mRNAs at low temperatures, thus enhancing the translation efficiency [28]. CspC and CspE are originally identified as the multicopy suppressors of the chromosomal partition defect of an E. coli muk B mutant [29]. Csp E has been shown to interact with nascent RNA in a complex with RNA polymerase [30]. Nakaminami et al. [31] determined the importance of C-terminal region of a plant Cold Shock Domain Protein (CSDP). They showed that deletion of all C-terminal zinc fingers in wheat WCSP1 abolished the growth stimulatory activity in E. coli during cold stress indicating that the CCHC-type zinc fingers in CSDPs are highly vital for growth.

\section{Cold shock proteins and abiotic stress tolerance}

CspA regulates its own synthesis by binding to RNA hair pin (cold box) and suppresses gene expression [32]. CspA is significantly induced in harsh condition of cold, acidic, oxidative stresses in Brucella melitensis, the most dangerous pathogen [33]. This suggests that CspA protects bacteria from multiple abiotic stresses. CspA isolated from Caulobacter crescentus is the most prominent for cold adaption in comparison with $\mathrm{CspB}$, and CspA deletion mutant showed major effect on growth at a lower temperature [34]. Bacillus CspB protein is a 67 amino acid, small, acidic protein, highly homologous with CspA, mostly binds to polypyrimidines in single stranded DNA strand, exponentially expressed during log phase and prevents cell damage during ice crystal formation [35]. CSPs are well conserved in bacteria, animals as well as in plants. In bacteria, Csps have one CSD, but in eukaryotes, Csps are flanked by $\mathrm{N}$ - and C-terminal domains. CSD homologs were also reported in eukaryotes, for example CSD shows high homology with human Y-box protein YB-1 and others [36,37].

E. colidisplay cold sensitivity during quadruple-deletion (CspA, CspB, CspE, and CspG), suggesting that CspA and its homologs protect the $E$. coli against cold stress conditions. Overexpression of all Csps except CspD (associated with starvation) resulted in the suppression of cold sensitivity in bacteria. Bacterial systems overexpressed with Csps have not been tried for tolerance to drought and multiple stresses given simultaneously. Also, overexpression of CspD resulted in lethality. The S1 domain of polynucleotide phosphorylase (PNPase) is a structural homolog of CspA and also suppresses the cold sensitivity of the mutant [38]. Thus, except CspD, other Csps appear to be vital for cold stress tolerance in bacteria. Plants also have Csp homologs, and play a pivotal role in growth, development and stress adaptations too [12]. However, studies dealing with overexpression of plant Csps are meager.

\section{Pleiotropic effects of Csps and its homologs}

CSPs help in bacterial growth under low temperature conditions [39]. Bacterial Csps act as chaperones to destabilise mRNA secondary structures and enhance the translation process $[21,40,41]$. Csps allow mRNAs to efficiently translate at low temperatures and also regulate transcription and transcription antitermination there by maintain mRNA stability [42]. CspA, the most induced Csp accounts for $13 \%$ of the total cellular protein at low temperatures [13]. CspA also regulates its own synthesis at $37{ }^{\circ} \mathrm{C}$ and cold by premature termination of unusual long $5^{\prime}$ UTR, a binding site of regulatory proteins [43]. CspA (cold-shock DEAD-box protein A) RNA helicase destabilize the secondary RNA structures during cold temperature involve in the biogenesis of the 50Sribosomal subunits [44]. Wang et al. [17] found that CspA and CspB genes are vital for microbial growth under cold stress. Jiang et al. [28], Graumann and Marahiel [37] pointed out both CspA and CspB increase the protein translation in cold conditions through the elimination of stabilized RNA secondary structures. Castiglioni et al. [45] expressed CspA and CspB genes in maize which conferred abiotic stress tolerance with improved grain yield. Likewise, improved drought stress tolerance in wheat was noticed with the overexpression of synthetic bacterial cold shock protein gene Se CspA [46]. It is observed that E. coli CspE functions as anti-terminator in transcription and efficiently increases expression of the gene [47]. But, CspD suppress growth at stationary phase, inhibits the oriC replication, through prepriming complex formation [48].

Hunger et al. [49] found out that CSPs work in concert with a DEAD box helicase to rescue misfolded mRNA and help in transcription [50]. Bae et al. [51] showed that $\operatorname{CspA}, \mathrm{CspC}$, and $\mathrm{CspE}$ genes act as antiterminators and regulate the expression of cold-inducible genes. Plants have CSD proteins which differ from that of CSPs that are known to occur in prokaryotes [52]. Several of the bacterial CSPs and plant CSDs were found induced under cold stress conditions [53,54]. Interestingly, though E. coli CSPs are responsive to cold stress and function as RNA chaperones [37], they share a domain with AtCSP3, which plays a pivotal role in low temperature tolerance as noticed by Kim et al. [55]. Park et al. [56] showed that CSDPs affect seed germination and growth of Arabidopsis plants under abiotic stress. It has been 
suggested by Sasaki \& Imai [52] that CSDPs regulate embryo development, flowering time and fruit development indicating their diverse roles in plants unlike that of bacteria. Melencion et al. [57] demonstrated an RNA chaperone function of a universal stress protein in Arabidopsis which displayed enhanced cold stress tolerance in plants. E. coli CspA and CspB genes increased cold tolerance when overexpressed in Arabidopsis thaliana [46].

This suggests that the synthetic genes had identical functions to Arabidopsis AtCSP3 in imparting cold stress tolerance [46]. Conversely, SeCspA and SeCspB did not improve cold stress in transgenic wheat but showed that synthetic CspA gene improves drought stress under the field conditions [46]. Sasaki et al. [58] showed that Arabidopsis AtCSDP2 negatively regulates freezing tolerance. Further, they demonstrated that overexpression of AtCSP2 resulted in reduced salt stress tolerance in Arabidopsis, indicating that it is a negative regulator of salt stress. It may be noted here that $E$. coli CSPs share a domain with Arabidopsis AtCSP3. Overexpression of AtCSP3, which shares a E. coli CSP domain resulted in improved salt and drought stress tolerance by upregulating the expression of stress related proteins [59]. Yu et al. [46] showed that overexpression of CspA and CspB genes caused the upregulation of TaCDPK3 transcription factor in wheat. It is known that CDPKs play vital roles in stress signal transduction and regulate the downstream genes that can be activated in turn by ABA [60].

\section{Conclusions}

Food production needs to be addressed with an ever increase in population and decrease in natural resources. Development of plants which can withstand adverse conditions is certainly the need of the hour. Csps act as molecular chaperones and protect bacteria from cold shock conditions. Csps are the promising genes which involve a cross talk between cold, salt, and drought stresses and are efficient in developing plant resilience. Csps are abundantly found in bacteria and are constitutively expressed during stress conditions. Transgenic plants overexpressing bacterial Csps have been found to be tolerant to cold, salt, and drought stresses. Thus, Csps are efficient chaperons, but need to be exploited further for developing transgenic plants that are resilient to the changing environment.

\section{Author contributions}

RG conceived and written the manuscript. SAK, PHK and PBK have gone through the MS critically and refined it.

\section{Conflict of interest}

Authors declare no conflict of interest.

\section{Acknowledgement}

This research was supported by the Department of Science and Technology, SERB, New Delhi, Government of India, through the order F.No. SERB/SB/SO/PS/104/2013. We gratefully acknowledge the financial assistance provided to RG. PBK acknowledges the financial assistance provided by the CSIR, New Delhi in the form of Emeritus Scientist.

\section{References}

1. Phadtare S, Severinov K (2010) RNA remodeling and gene regulation by cold shock proteins. RNA Biol 7(6): 788-795.

2. Phadtare S (2004) Recent developments in bacterial cold-shock response. Curr Issues Mol Biol 6(2): 125-136.

3. Hébraud M, Potier P (1999) Cold shock response and low temperature adaptation in psychrotrophic bacteria. J Mol Microbiol Biotechnol 1(2): 211-219.

4. Yamanaka K, Fang L, Inouye M (1998) The CspA family in Escherichia coli: multiple gene duplication for stress adaptation. Mol Microbiol 27(2): 247-255.

5. Charollais J, Dreyfus M, Iost I (2004) CsdA, a cold-shock RNA helicase from Escherichia coli, is involved in the biogenesis of $50 \mathrm{~S}$ ribosomal subunit. Nucleic Acids Res 32(9): 2751-2759.

6. Phadtare S (2012) Escherichia coli cold-shock gene profiles in response to over-expression/deletion of CsdA, RNase R and PNPase and relevance to low-temperature RNA metabolism. Genes Cells 17(10): 850-874.

7. Jones PG, VanBogelen RA, Neidhardt FC (1987) Induction of proteins in response to low temperature in Escherichia coli. J Bacteriol 169(5): 2092-2095.

8. Graumann P, Marahiel MA (1996) Some like it cold: response of microorganisms to cold shock. Arch Microbiol 166(5): 293-300.

9. Phadtare S, Inouye M (1999) Sequence-selective interactions with RNA by CspB, CspC and CspE, members of the CspA family of Escherichia coli. Mol Microbiol 33(5): 1004-1014.

10. Kim WS, Khunajakr N, Ren J, Dunn NW (1998) Conservation of the major cold shock protein in lactic acid bacteria. Curr Microbiol 37(5): 333-336.

11. Derzelle S, Hallet B, Francis KP, Ferain T, Delcour J, et al. (2000) Changes in cspL, cspP, and cspC mRNA abundance as a function of cold shock and growth phase in Lactobacillus plantarum. J Bacteriol 182(18): 5105-5113.

12. Mani A, Gupta DK (2015) Phylogenetic studies on plant cold shock domain proteins. International Journal of Advances in Science Engineering and Technology 3(2): 13-14.

13. Goldstein J, Pollitt NS, Inouye M (1990) Major cold shock protein of Escherichia coli. Proc Natl Acad Sci U S A 87(1): 283-287.

14. Etchegaray JP, Jones PG, Inouye M (1996) Differential thermoregulation of two highly homologous cold-shock genes, $\operatorname{cspA}$ and $\operatorname{cspB}$, of Escherichia coli. Genes cells 1(2): 171-178.

15. Nakashima K, Kanamaru K, Mizuno T, Horikoshi K (1996) A novel member of the cspA family of genes that is induced by cold shock in Escherichia coli. J Bacteriol 178(10): 2994-2997.

16. Yamanaka K, Inouye M (1997) Growth-phase-dependent expression of cspD, encoding a member of the CspA family in Escherichia coli. J Bacteriol 179(16): 5126-5130.

17. Wang N, Yamanaka K, Inouye M (1999) CspI the ninth member of the CspA family of Escherichia coli, is induced upon cold shock. J Bacteriol 181(5): 1603-1609.

18. Bae W, Phadtare S, Severinov K, Inouye M (1999) Characterization of Escherichia coli cspE, whose product negatively regulates transcription of cspA, the gene for the major cold shock protein. Mol Microbiol 31(5): 1429-1441.

19. Horn G, Hofweber R, Kremer W, Kalbitzer HR (2007) Structure and function of bacterial cold shock proteins. Cell Mol Life Sci 64(12): 1457-1470. 
20. Kim J, Ha S, Park W (2018) Expression and deletion analyses of cspE encoding cold-shock protein E in Acinetobacter oleivorans DR1. Res Microbiol 169(4-5): 244-253.

21. Keto-Timonen R, Hietala N, Palonen E, Hakakorpi A, Lindström M, et al. (2016) Cold shock proteins: a minireview with special emphasis on Csp-family of enteropathogenic Yersinia. Front Microbiol 7: 1151.

22. Jin B, Jeong KW, Kim Y (2014) Structure and flexibility of the thermophilic cold-shock protein of Thermus aquaticus. Biochem Biophys Res Commun 451(3): 402-407.

23. Mitta M, Fang L, Inouye M (1997) Deletion analysis of $\operatorname{cspA}$ of Escherichia coli: requirement of the AT-rich UP element for cspA transcription and the downstream box in the coding region for its cold shock induction. Mol Microbiol 26(2): 321-335.

24. Giuliodori AM, Di Pietro F, Marzi S, Masquida B, Wagner R, et al. (2010) The cspA mRNA is a thermosensor that modulates translation of the cold-shock protein CspA. Mol cell 37(1): 21-33.

25. Mega R, Manzoku M, Shinkai A, Nakagawa N, Kuramitsu S, et al. (2010) Very rapid induction of a cold shock protein by temperature downshift in Thermus thermophilus. Biochem Biophys Res Commun 399(3): 336-340.

26. Lopez MM, Makhatadze GI (2000) Major cold shock proteins, CspA from Escherichia coli and CspB from Bacillus subtilis, interact differently with single-stranded DNA templates. Biochimica et Biophysica Acta 1479(1-2): 196-202.

27. Kremer W, Schuler B, Harrieder S, Geyer M, Gronwald W, et al. (2001) Solution NMR structure of the cold-shock protein from the hyperthermophilic bacterium Thermotoga maritima. Eur J Biochem 268(9): 2527-2539.

28. Jiang W, Hou Y, Inouye M (1997) CspA, the major cold-shock protein of Escherichia coli, is an RNA chaperone. J Biol Chem 272(1): 196-202.

29. Yamanaka K, Mitani T, Ogura T, Niki H, Hiraga S (1994) Cloning, sequencing, and characterization of multicopy suppressors of a mukB mutation in Escherichia coli. Molecul Microbiol 13(2): 301-312.

30. Hanna MM, Liu K (1998) Nascent RNA in transcription complexes interacts with $\mathrm{CspE}$, a small protein in E. coli implicated in chromatin condensation. J Mol Biol 282(2): 227-239.

31. Nakaminami K, Karlson DT, Imai R (2006) Functional conservation of cold shock domains in bacteria and higher plants. Proc Natl Acad Sci U S A 103(26): 10122-1027.

32. Rennella E, Sára T, Juen M, Wunderlich C, Imbert L, et al. (2017) RNA binding and chaperone activity of the E. coli cold-shock protein CspA. Nucleic Acids Res 45(7): 4255-4268.

33. Wang Z, Wang S, Wu Q (2014) Cold shock protein A plays an important role in the stress adaptation and virulence of Brucella melitensis. FEMS Microbiol Lett 354(1): 27-36.

34. Mazzon RR, Lang EA, Silva CA, Marques MV (2012) Cold shock genes $\operatorname{cspA}$ and cspB from Caulobacter crescentus are post-transcriptionally regulated and important for cold adaptation. Journal of Bacteriology 194: 6507- 6517 .

35. Willimsky G, Bang H, Fischer G, Marahiel MA (1992) Characterization of $\mathrm{CspB}$, a Bacillus subtilis inducible cold shock gene affecting cell viability at low temperatures. J Bacteriol 174(20): 6326-6335.

36. Wolffe AP (1994) Structural and functional properties of the evolutionarily ancient Y-box family of nucleic acid binding proteins. Bioessays 16(4): 245-251.

37. Graumann PL, Marahiel MA (1998) A superfamily of proteins that contain the cold-shock domain. Trends Biochem Sci 23(8): 286-290.

38. Xia B, Ke H, Inouye M (2001) Acquirement of cold sensitivity by quadruple deletion of the cspA family and its suppression by PNPase S1 domain in Escherichia coli. Mol Microb 40(1): 179-188.
39. Blattner FR, Plunkett G, Bloch CA, Perna NT, Burland V, et al. (1997) The complete genome sequence of Escherichia coli K-12. Science 277(5331): 1453-1462.

40. Bae W, Jones PG, Inouye M (1997) CspA, the major cold shock protein of Escherichia coli, negatively regulates its own gene expression. J Bacteriol 179(22): 7081-7088.

41. Wouters JA, Rombouts FM, de Vos WM, Kuipers OP, Abee T (1999) Cold shock proteins and low-temperature response of Streptococcus thermophilus CNRZ302. Appl Environ Microbiol 65(10): 4436-4442.

42. Hofweber R, Horn G, Langmann T, Balbach J, Kremer W, et al. (2005) The influence of cold shock proteins on transcription and translation studied in cell-free model systems. FEBS J 272(18): 4691-4702.

43. Fang L, Jiang W, Bae W, Inouye M (1997) Promoter independent cold-shock induction of cspA and its derepression at $37{ }^{\circ} \mathrm{C}$ by mRNA stabilization. Mol Microbiol 23(2): 355-364.

44. Jones PG, Mitta M, Kim Y, Jiang W, Inouye M (1996) Cold shock induces a major ribosomal-associated protein that unwinds double-stranded RNA in Escherichia coli. Proc Natl Acad Sci U S A 93(1): 76-80.

45. Castiglioni P, Warner D, Bensen RJ, Anstrom DC, Harrison J, et al. (2008) Bacterial RNA chaperones confer abiotic stress tolerance in plants and improved grain yield in maize under water-limited conditions. Plant Physiol 147(2): 446-455

46. Yu TF, Xu ZS, Guo JK, Wang YX, Abernathy B, et al. (2017) Improved drought tolerance in wheat plants overexpressing a synthetic bacterial cold shock protein gene SeCspA. Sci Rep 7: 44050.

47. Phadtare S, Inouye M, Severinov K (2002) The nucleic acid melting activity of Escherichia coli $\mathrm{CspE}$ is critical for transcription antitermination and cold acclimation of cells. J Biol Chem 277(9): 7239-7245.

48. Yamanaka K, Zheng W, Crooke E, Wang YH, Inouye M (2001) CspD, a novel DNA replication inhibitor induced during the stationary phase in Escherichia coli. Mol Microbiol 39(6): 1572-1584.

49. Hunger K, Beckering CL, Wiegeshoff F, Graumann PL, Marahiel MA (2006) Cold-induced putative DEAD box RNA helicases CshA and CshB are essential for cold adaptation and interact with cold shock protein B in Bacillus subtilis. J Bacteriol 188(1): 240-248.

50. El-Sharoud WM, Graumann PL (2007) Cold shock proteins aid coupling of transcription and translation in bacteria. Sci Prog 90(1): 15-27.

51. Bae W, Xia B, Inouye M, Severinov K (2000) Escherichia coli CspAfamily RNA chaperones are transcription antiterminators. Proc Natl Acad Sci U S A 97(14): 7784-7789.

52. Sasaki K, Imai R (2012) Pleiotropic roles of cold shock domain proteins in plants. Front plant sci 2:116.

53. Sasaki K, Kim MH, Imai R (2007) Arabidopsis cold shock domain protein2 is a RNA chaperone that is regulated by cold and developmental signals. Biochem Biophys Res Commun 364(3): 633-638.

54. Jung YH, Yi JY, Jung HJ, Lee YK, Lee HK, et al. (2010) Overexpression of cold shock protein A of Psychromonas arctica KOPRI 22215 confers cold-resistance. protein J 29(2): 136-142.

55. Kim MH, Sasaki K, Imai R (2009) Cold shock domain protein 3 regulates freezing tolerance in Arabidopsis thaliana. J Biol Chem 284(35): 23454-23460.

56. Park SJ, Kwak KJ, Oh TR, Kim YO, Kang H (2009) Cold shock domain proteins affect seed germination and growth of Arabidopsis thaliana under abiotic stress conditions. Plant Cell Physiol 50(4): 869-878.

57. Melencion SM, Chi YH, Pham TT, Paeng SK, Wi SD, et al. (2017) RNA chaperone function of a universal stress protein in Arabidopsis confers enhanced cold stress tolerance in plants. Int J Mol Sci 18(12): 2546. 
58. Sasaki K, Liu Y, Kim MH, Imai R (2015) An RNA chaperone, AtCSP2, negatively regulates salt stress tolerance. Plant Signal Behav 10(8): e1042637.

59. Kim MH, Sato S, Sasaki K, Saburi W, Matsui H, et al. (2013) COLD SHOCK DOMAIN PROTEIN 3 is involved in salt and drought stress tolerance in Arabidopsis. FEBS Open Bio 3: 438-442.
60. Sanders D, Pelloux J, Brownlee C (2002) Calcium at the crossroads of signaling. Plant Cell 14: 401-417.

\section{Your next submission with Juniper Publishers will reach you the below assets}

- Quality Editorial service

- Swift Peer Review

- Reprints availability

- E-prints Service

- Manuscript Podcast for convenient understanding

- Global attainment for your research

- Manuscript accessibility in different formats

( Pdf, E-pub, Full Text, Audio)

- Unceasing customer service

Track the below URL for one-step submission https://juniperpublishers.com/online-submission.php 